\title{
HOW MUCH IS AN IMAGE WORTH?
}

\begin{abstract}
The paper discusses the problem of "competition" between the image and the articulated language/text. The problem as such is historical and it reflects the change between the language based communication (including the radio era) and the mainly image based communication. Opposing to those who equate the image construction in the information and communication technology with the impoverishment of meanings and necessity and ability of logical/rational discourse, the arguments of these two positions are analysed. The paper mentions the difference between representation, image and idea, analyses some arguments related to the logical articulation of words in texts, and to the specific imagistic manner of communication, and concludes that the text and image are complimentary, and that their worth depends on the meanings they transmit and the quality of meanings/values they transmit. In this respect, the diminishing of preoccupations, of ability and time for logical articulation of the reference to the world means the decline of man. At the same time, the theory highlighted in the paper does not counter the "bad" image to the "good" text (and certainly, nor vice versa), but the measure in their use according to the scale of goals and means which people must have.
\end{abstract}

Keywords: image, representation, articulated language, text, logic, virtual, IT, video games, literacy/illiteracy.

\section{In Lieu of Introduction}

So, how much is an image worth? An image is worth a lot. It is worth infinitely: for all of us - and the model of this regard is given by our thought about a visually impaired person, about the extreme state of man having the severest physical disability in relation to the feeling of life - the direct reception of the images of reality is the ideal and necessary condition for happiness. And I am not referring here to the fact that this latter concept reflects subjective states, therefore that it is possible for a visually impaired person to be happy also in the absence of sight, but to the mutual complementation of da- ta provided by the sense organs and the definition of human sensibility depending on the degree of mutual complementation of his sense organs. Berkeley had long proven that sight is "epistemologically" superior to the other sense organs because it provides the profoundest data on reality (colours, nuances, shades and lights, distance, space beyond the perceptible limit by touching (Berkeley, 1733, pp. 9-60) and also because it equips man with the first language: that in which the reproduction sign of reality is reality itself ${ }^{1}$. Just like all languages, including

\footnotetext{
Language is a set of signs for the designation and knowledge of reality, and the familiarity - through
} communication - with a sound/sound compounds 
the natural one, the language of sight can be educated and developed, but the ideas generated with the help of the language of touch and the language of sight - so as a result of perceiving the world through touching or seeing - are never common, they are completely different even if they refer to the same objects ${ }^{2}$. For this reason, senses are not mutually substitutable for a

for one aspect or another of reality has taken place (and takes place in the learning of human language by young children) in connection with focusing sight on one aspect or the other and with pointing out to those to whom the aspect of reality/the discovery of this aspect is communicated: "here"/the aspect is pointed out. Once the natural/articulated language was acquired, the gesture of showing, of directing the sight of others disappeared, but the primordial character of seeing reality has been translated into the further use of the verb to see with the meaning to understand.

Rousseau emphasized that the sound language appeared because touching (others to communicate something) and feeling are limited to presence and the presence of objects, namely at "arm's length", and also that sight as a means of communication is limited to the radius of such sight in a certain space; for this reason, voice - which is addressed to the ear and to a person located farther, and which refers to things seen - became a more effective means of communication than gesture, and the premise of communication was, of course, need: but it was not the need to share knowledge, but the need to manifest different passions (love, hatred, pity, wrath) (see Rousseau, 1781/1856, pp. 495, 497).

And, interestingly, because of the affects, the first words had not been words for literal descriptions, but figurative ones. Rousseau's example (p. 498) was that of a man who, because he was afraid of other people he met, called them giants, and only then he coined the word that included himself and the others, as men/people.

The articulated character of language has developed from the unarticulated language, that of onomatopoeia, and that is why Cratylus, Plato's character, who claimed that terms have an intrinsic truth which is not dependent on the will/conventions of people, is not altogether untrue (p. 499, Rousseau).

(Berkeley, 1708, fragm. 95, 99): "but the proper objects of vision make a new set of ideas, perfectly distinct and different from the former, and which can in no sort make themselves perceived by touch... the connexion there is between the several ideas of sight and touch, he will be able, by the perception he has of the situation of visible things in respect of one another, to make a sudden and true estimate of the situation of outward, tangible things corresponding to them. And thus it is he shall per- normal person and sight is the most important sense and the most painful to be replaced in case of any malfunctions.

But how much are words, oral or written articulated language worth? Just as much ${ }^{3}$, it is worth infinitely. Because, being connected to sight, to the direct experience of the existence of the phenomenon, man interprets with the help of language whatever he sees, namely he transforms the copy of the phenomenon, as it is perceived through sight, into logos, into understanding $^{4}$. In other words, the competition between images and oral language, between images and text had never become a philosophical topic since philosophy deals with human beings holistically, in an integrative manner - unless the change starting with the second half of the $20^{\text {th }}$ century would have occurred, change which promoted the primacy of visual communication/communication through images over written language. But because it occurred, and although conjectural, the issue must be deciphered with the help of instruments which investigate beyond the disclosure of the relevant conjecture. The purpose of this article is precisely to contribute to this deciphering.

On the other hand, the reply to the question in the title - how much is an image worth? - is

ceive by sight the situation of external objects which do not properly fall under that sense."

3 For this "just as much", see Aristotle who considered the language as a sign of the things which are unseen/are not present when people want to show them even with words: symbols of things. And writing is, in this respect, not so much a sign of language - leaving aside the written transcription of written words - but also a sign of things.

4 (Plato, "Cratylus", 399a): "The name 'man' ( $\alpha v \theta \rho \omega \pi \mathrm{s})$ indicates that the other animals do not examine, or consider, or look up at ( $\alpha \dot{\alpha} \alpha \theta \rho \varepsilon \tilde{)})$ any of the things that they see, but man has no sooner seen-that is, ö $\pi \omega \pi \varepsilon$ - than he looks up at and considers that which he has seen. Therefore of all the animals man alone is rightly called man

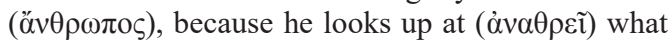
he has seen (ö $\pi \omega \pi \varepsilon)$." 
not a difficult one, and the article assumes this reply: the value of an image depends on its contents and, in broader terms, on the message delivered. In the wake of the Kantian constructivism, one can claim that an image is not neutral, a mere copy of the empirical or imagined reality, realized by technical means, (an image is not thus the "victory of sophisticated technique over the traditional natural livelihood and over the traditional natural communication") but that it is filled with the extra-technical intentions of its creators, or more precisely of those controlling the image generation process (in broader terms, the communication process). The use of images - or of any other means of communication - is connected to these initial intentions, because such use is the result of goals and target oriented intentions of those who are at the origin of input. The decline of the logical and cultural abilities of the cohorts of television viewers watching endless and incredibly low quality television shows is not to be blamed, first of all, on those television viewers, but: i) on their general education conditions which they do not control and ii) on the decision-makers controlling the broadcasted images and the education conditions in general. Those who deplore the audience of these shows and blame the cohorts of television viewers who are passively watching them are moral Pharisees and intellectually incapable of linking the input to the output.

\section{The Image Suggested by Belles-Lettres versus Articulated Discourse}

Evidencing the descriptive, therefore suggestive, power of belles-lettres/fictional literature compared to that of information transmitted by journalists and politicians and also compared to that of the mushy moral theory,
Marx sided with the first alternative ${ }^{5}$. It is the first from a historical and informational point of view too. But what are the grounds of such a position? And, on the other hand, isn't there a common ground between fictional literature and social information and messages?

The representation of phenomena, namely the connection of various aspects perceived as a coherent ensemble which reflects those phenomena, in fact identifies them in the overwhelming sea of the world. If we want a synonym - and we always want one, because otherwise the explanation is almost impossible to realize - then we define the representation as image or meaning of the phenomenon. But of course, people do not stop at identifying isolated phenomena, but because they always want to understand the world presented to them, they connect these phenomena, i.e. their representations, and thus they get an idea of things.

In colloquial terms, some people are tempted to assimilate representations to ideas. In fact, they mutually correspond to one another. Nevertheless, ideas are not mere representations, because they are already structured at the level of logic or of the mental mechanism of logic. For this reason, the representation is situated between the moment of observation and the moment of logic (Moscovici, 2000, pp. 208$231)$ : i.e., it is a mental reproduction of phenomena, and because representations are articulated, a word corresponds to each representation. As we know, the words already represent small theories for people, namely certain simple knowledge concerning the respective phenome-

\footnotetext{
5 Marx (1854): "The present splendid brotherhood of fiction-writers in England, whose graphic and eloquent pages have issued to the world more political and social truths than have been uttered by all the professional politicians, publicists and moralists put together."
} 
non. Nevertheless, again, words as such are not yet theories: namely, they are not concepts transmitting a complex meaning which people are aware of and which reflect the generality, i.e. the general nature of certain connections between things or aspects which help the understanding of corresponding words and phenomena. (The theory is, in this case, a coherent and plausible notion - irrespective if it includes only hypotheses or if it is formulated in a controversial/eristic manner - therefore a coherent and plausible connection between ideas about phenomena and which outlines a general perspective, thus also a highlight of causality and consequences.) Only concepts benefit from this nature of "being theory".

In simpler terms, words are names ${ }^{6}$, verbal identifications of phenomena, while concepts are more than names; they are those theories of things ${ }^{7}$.

6 Let us remember Plato, "Cratylus"; and Aristotle, Metaphysics, Zeta/VII, 1029b, 1030a; 1031b, 1032a; 1034b; 1035a; 1037b; Aristotle, "Categories", 1a, 1b; and especially "De interpretatione", I, $16 \mathrm{a}, 16 \mathrm{~b}$.

7 Therefore, the concept is necessary in the sense that it means something about things, i.e. it is not arbitrary as a name/a designation, according to (Deleuze, 1969, p. 26). Philosophical analysis does not split hairs, it distinguishes however between the fact that articulated language designates - and there it is, we see and we shall see how important it is to know the name of things, if we don't know them we cannot refer to things and we remain at the level of the unexpressed and beyond expression - and, at the same time, reveals meanings of what it designates, namely the implication that the name given to one thing refers to that thing and, therefore that the name assigned to a thing involves in itself the universal and the general, i.e. the theory, in my view/wording.

"The cherry tree blossomed" is a sentence in which we can notice:

a) the name (cherry tree, blossomed), therefore the consciousness that language assumes the existence of the speaking subject in relation to an object,

b) the personal manifestation (myself or anyone else, including the impersonal "people say that" " it is said that"), namely the speaking man's presence in the act of language,
If we think, for example, about our argumentation/our judgments - which is/are always propositional, this is the only manifestation of the logical connection of things - then we understand better: in our argumentation we connect different empirically noticeable things; these things as such do not represent arguments, but only our inference in relation to them; arguments pertain to the already logical registry of the mind; on the contrary, observed empirical phenomena are "seen"/felt with the help of representations or through images corresponding to such phenomena and which are specific systems

c) the meaning of the sentence (that the sentence and the names used refer to possible things, precisely because in the background, therefore in the consciousness, we know that there exist cherry trees, trees, which are life forms and which, therefore, feed and multiply etc.), (and the meaning is the condition of truth (Deleuze, 1969, p. 25), because it refers precisely to the name which designates things, namely the association of the words "cherry tree" and "blossomed" is not absurd),

d) and the sense (which refers to the unitary intention of the sentence (to its expressed, Deleuze, p. 33), and to the fact that the things designated by the sentence can exist as declared in that respective sentence. The sense is, therefore, always of the sentence, and not of the term (which has a meaning), namely it connects the sentence and the things it refers to (things which we imply behind words, that is precisely the reason why we use them in that sentence).

What is the reason of this long footnote? It is that to understand that if man does not practice his articulated language, he: a) no longer has sufficient words to designate things, b) uses words also by copying messages received from anywhere, namely he does not discern the meanings of words/he is unaware of the meaning of words, c) he does not distinguish between the paternity of messages and mixes and assimilates various sources, in the sense that he may assume something absurd/harmful, d) he does not understand the connection between messages and things, seeming irrelevant to him if he claims anything/assumes any statement. And if we take into consideration that any sentence describes an event/is an event (Deleuze, 1969, p. 34), the poverty of articulated language makes man unable to discern events and he is unresponsive towards them.

For this reason, practicing articulated language also means practicing logic and critical spirit: towards sentences and towards things. 
of synapses configuring more or less coherent information units; these information units are expressed through words, concepts and judgments which use the above-mentioned bricks (words and concepts).

The shift from representations to ideas and concepts is the natural consequence of the fact that people want to understand not only isolated phenomena, but their actual existence in the world: and this actual existence is always a set of connections. Of course, once ideas are known, representations acquire a larger meaning, but yet again, ideas are an interpretation of representations and the acquisition of deeper, more general meanings, beyond the mere reproduction of existence/beyond experience.

Furthermore: if representations/mental images/ideas ${ }^{8}$ are awoken by judgments of things, and the more complicated these judgments (spoken or written) because they entail $n$ intermediary judgments - consequently, the more complex the theory (complex meaning) transmitted through judgments - then the more complicated the judgments, the more difficult things seem to us and the more difficult to coagulate representations or our ideas in relation to them. Once again: because theory /judgments consider complex and always rather indirect connections between things.

As a result, it is obvious that images of empirical phenomena which are better understood thanks to their particular nature (and precisely individual circumstances are described by belles-lettres, and precisely this simplicity of the individual allows for aesthetic and moral emotion) are more suggestive than theories which are always general in terms; because theories

8 The difference between representation and idea is not important in this case. are, above all, even generalizations made by people after $n$ representations of the circumstances inciting their interest. Representations concerning the phenomena described in novels thus function as clearer and more suggestive images, which epitomize the representations and theories made by people about things in a simpler and more striking way. Of course not any image produced by fictional literature is kept as important in the collective memory: in other words, not any image which the receiver knows for sure is fiction is generating a theory, a concept about those respective phenomena. Because - and I must mention - and, of course, leaving aside the theories of artistic images as such, of their creation and power of significance, people are interested in the real life, namely they make (first of all) notions/theories of real phenomena, and not of the representations in their minds in connection to these phenomena.

But these representations are so important - in the sense that they mediate between real life and the theories people make about life that their control became, and even more so in late modernity, one of the most efficient weapons for the control/domination of people by people.

Anyway, images must be significant, must have substance - as a result, also having a strong individualizing trend and also a modeling trend, i.e., openness towards a generalizing ability of the human cognition - in order to generate theories about the world, meanings about "how things work".

Just as in the same manner images must be credible, plausible: if they are not - as is the case of representations and theories transmitted by many politicians, or as is the case of fictions in which circumstances are improbable and 
solutions are always brought about by deus ex machina - then these images are not remembered as a basis of worldviews. They are entertainment of waste of time, namely noise, informational ballast which ultimately represents a pollution of people's minds having inherently negative consequences.

\section{Image versus Words}

The contraposition of insipid political discourse to memorable pages in the written literature seems to have been specific to the industrial revolution of the $19^{\text {th }}$ century and to the humanist trust in the power of the written word to bring about into modernity the millions of working people necessary for this revolution; and, at the same time, to domesticate them: as if all the readers are/were friends in a literary society (Sloterdijk, 2009); and although domestication is a metaphor for domination relations, it was connected, since the oldest times, to the selfdomestication of the species, to the development of sedentary manners of life, shelters/homes which allowed the constitution of theory, namely of the contemplation of the world through the windows behind which people felt safe enough to theorize (Sloterdijk, 2009, p. 21); namely, only domestication as dressage, and not as taming, as humanization, was the process in relation to which thinkers remained silent and which idealists thought it would be annulled through the reading of "right books" to which process they transferred the power of people to think on their existence; but the enrolment in a literary society, the reading, are not sufficient for people to think about the dressage and oppose it: people behind reading, those who choose it must be pointed out in order for the discourse (which people will read) to highlight the difference between domes- tication and dressage/"submitting" (Sloterdijk, 2009, p. 26) of the subjects so that they be docile continuators of the dressage; and of course, without the "empowering knowledge", i.e. without cultural instruments - among which the writing-reading ability is fundamental - people irremediably remain dominated and subjected.

And there it is, the development of industrial modernity - let us not forget, the concept of modernity does not refer to a neutral timeframe, but to the capitalist level of social relations led, first of all not due to taming, but due to (consumerist) dressage, to finding a more efficient means than reading: the image. A picture is worth a thousand words ${ }^{9}$ reminds us of the comment - since 1911, 1913 and, in connection with the war propaganda, 1918 - made by American advertisement experts regarding the fact that for persuasion an image is worth more than a text. The praising of images more than the text continued after the First World $\mathrm{War}^{10}$, after an already glorious practice of photography and, of course, during the adolescent enthusiasm of the silent film.

And today, after several decades of neoliberal offensive - in the pursuit of buyers to allow the resuming, if not the expansion, of profit generating production and the ensuring of new debtors for the banks which granted them loans - the ads/commercials, already named only advertising, flood every inch of the public space and every second of the individual time dedicated to information and culture: on the Internet, ads are delivered to private email accounts, are found on the page of every infor-

9 See: A Picture... Retrieved October 12, 2017 from: https://en.wikipedia.org/wiki/A picture is worth a thousand words.

10 See: The History of a Picture's Worth. Retrieved May 17, 2018 from: http://www2.cs.uregina.ca/ hepting/research/web/w ords/history.html. 
mation article together with films and information concerning cultural events.

Leaving economic interest aside, why are static ads or TV commercials considered to be worth more than a text/1000 words? Because the image of commercials - accompanied maybe by a few words, but most of the times without any words at all - is "more suggestive" now for the population systematically alienated from written culture and aligned to an orality that does not represent in any way a synthesis of historical moments of orality and written culture, therefore it is not and it does not attest a superior cultural level after those mentioned, but on the contrary a reduction/ simplification/ infantilization of people, by stimulating their consumption desires hic et nunc. Even speeches especially those of politicians, which fill in the gaps between images provided for entertainment purposes - are rapidly floating around, people are (possibly) listening to them but they do not have time to judge them profoundly because the television provides new and new speeches, issues never analyzed, followed and resolved, and entertainment, only entertainment (Postman, 2005). And the words used - in speeches, in films, in articles, in TV commercials - are few, simplistic (slogans, clichés), incorrectly expressed and used: they just show, describe, declare, but - obviously - they do not analyze. Hence, words must not be idealized either: they can transmit - in speeches or in a written text - absolutely illogical perspectives, and not only from the standpoint of a savant attitude about the world; and thus illogicality is the form of truly harmful messages.

Messages from the images generate, of course, states of mind, emotional reactions: exactly what the people ordering the images envisage. But these messages, less and less mani- fested in an articulated manner, generate less and less meanings/significances. Because these meanings are always brought about by articulated language and by its logical manifestation; moreover, even because the meaning of an image is manifested in an articulated manner in a person's mind - and of course, in the interpersonal dialogue - and the bombardment with images and the depletion of the offer of words and analysis leads to the poverty of the bundle of words and of the analytical capacity to connect them, people find themselves in a situation in which they have and they can express fewer and fewer meanings ${ }^{11}$. But the human logos is, before anything else, a representation of the logos of the world, is it not? This was the explanation provided since antiquity. Thus, the poverty of meanings means the inability to represent the world. What does this situation look like? And are we still surprised that there are manifestations for legalizing drugs? ${ }^{12}$

And nevertheless: an image - and especially to the extent and in the form in which it reproduces - helps the increase of information which people has, the increase of their perspective on existence and, accordingly, the increase of their cultural level. Not only images oppose the written text and the logical ability to com-

11 Someone said that the ideal of the scientific precision would consist just in this simplification. Certainly, this opinion is, let say, eccentric. On the contrary, the ideal of scientific precision consists in having the clear and elegant form of the answers to - thus, the meanings of - the problems put in a precise manner; so not in simplifying the meanings related to those problems, but in disclosing those meanings. The fragmentary character of science has nothing to do with the impoverishing of the public/political supply of information and meanings.

12 Hanfparade in Berlin Auch Nichtkiffer demonstrieren für Legalisierung von Cannabis, 13.08.2016. Retrieved May 08, 2018 from: http://www.berlinerzeitung.de/panorama/20--hanfparade-in-berlinauch-nichtkiffer-demonstrieren-fuer-legalisierungvon-cannabis-24552910. 
municate. But as we arrived to understand the equal importance of text and image reproduced $n$ times and infiltrating every house and every human brain, as we must pay attention to not blame the image or the text for the current configuration of people. Simply, the historical opportunity of the "mechanical reproduction" (Benjamin, 1936) of man's creative manifestations, thus the opportunity created at the level of technique, is used more capitalisto and hijacked/misapplied.

\section{Image and Idea}

The representation as simple image/ meaning of isolated things is followed by the idea/theory: which is a connection and interpretation of several representations, with the function of being tested in the social dialogue, that is to say, to be authenticated. Because even the mere representation or image and theory have a symbol function, of model in relation to which phenomena is compared. But $a$ symbol is verifiable only to the extent it is articulated, narrated in inner language or out loud, namely only to the extent it is compared to other symbols and real phenomena. And this means that a striking and touching literary text, or the images of a film/or the film in its entirety do not disclose truths and are not assumed as life models unless the literary text and the film - as "symbols" - are judged by people (rapidly, with their inner voice, so we are not referring here to literary criticism), for that reason synthesized in an articulated, logical, coherent manner.

Furthermore, people, of course, get an idea about the world after they read a book or see a film. But they confront their ideas/theories in society, on a daily basis with real social problems and phenomena, and obviously with other people's theories. During this confrontation - inherently articulated - people mutually correct their theories/perspectives, because some theories prove to be insufficient or untrue, while others, those authenticated by practice, do emerge as true and more efficient.

Briefly, it is not representations or images that "battle each other", but theories, ideas: people confront theories, not images. The simplest messages of political speeches - and even if the propagandistic arsenal also includes suggestive images, caricatures, slogans - are theories, they transmit ideas, not images.

Probably the place where images are stronger than ideas is the slice of behavior. Children see a certain food related habit at their parents - for example, to add salt to the food on their plate, or to mix certain ingredients etc. and they acquire this model and will apply it, the habit enters the subconscious. Nevertheless, behavior is the result of social interactions, then of social education. At one point children/people confront their own model with the theories regarding the respective phenomenon: namely at that point there is a fight between a habit, determined by an image, and theory. It is not necessarily sure that theory will conquer the mere image, namely that it will change behavior: but if people understand that theory is true, even if its message is not assumed, then it is clear for them that theory is the true one, while the image is in fact only habit.

Hence, theory nevertheless conquers: in the ontological registry, where the value of an image is high only if integrated into rational theories; while an image can conquer only in the phenomenal registry. 


\section{Image and Articulated Discourse}

For this reason - we reply to the second question asked in chapter 2. - what is common both for the most beautiful pages of belleslettres and for the most vulgar political speeches is the fact that what they transmit are messages/bundles of meanings and senses connected and coherently created through articulated language: in the form of text or oral speeches ${ }^{13}$. Only this articulated language transmits "representations", i.e. mental reproductions of a certain understanding of real phenomena: people use as synonyms images and representations to underline the role of copying (image is a copy, isn't it?) reality.

Actually, our knowledge is not a mere copy or image of things, and consciousness is not a mere photography camera, it's about meanings which shape even images, it's about creating meanings through the internal dialogue of consciousness regarding the thing on which it focuses at one point or another and its "background". And because ideas are also things and because the internal dialogue of consciousness already operates with $n$ other images and ideas, all always provided within society, there also results both the social character of the object of consciousness (this object is not a mere copy) and the active character, of constructing the object by the consciousness (the consciousness is always the consciousness of something and there always exists the consciousness of the act as such (I think that.../I am aware that...));

As a result, people don't know copies. They know ideas/theories about things, namely certain ideas/theories which seem plausi-

13 See for the complexity of orality - and for the "mental landscape" in an age emphasized by orality (Darnton, 2010). ble/true to them in their space-time framework. People don't know images, they refer to images in their articulated theories. Images are suggestive only if one assigns them meaning, and this means that only if they are integrated into ideas/theories.

\section{Image and Language}

Knowledge/ideas/theories are formed in the mind with the help of language, and they are transmitted just in the same way. Natural language has created, as it is known, the symbolic (mathematical and logical) languages as well, in which signs have a clear meaning - just like in the natural language - and which can be transmitted coherently even autonomously (see the demonstration of a mathematical problem), but which is interpreted and connected to other theories or aspects from mathematics or symbolic logic also with the help of natural language. A sequence of formulas in a theory is sufficient for mathematicians to have a clear image of the respective theory, but essential for them is precisely this theory, namely the meanings they discover and fix through the respective formulas. For them it is important that symbols allow for a "purification" of reality, a revealing of the special essence of reality they aim for, a cutting of this ontological layer of reality which they could not achieve only with the help of natural language. Symbolic language with its rules corresponds to this layer, namely it basically renders in an articulated manner the way in which this layer is understood. Only metaphorically can this layer be named "mathematical image": in reality it is a theory or, more precisely, an unfinished set of theories.

However, besides this parenthesis about a symbolism which some people associate only to 
image, although it is clear that it's still language, the discussion on the value of image cannot be reduced only to phenomenal comparisons which occur under the same circumstances in which the discovery of cinematography occurred and especially of television and IT which broadcast visual images - about the offensive of non-verbal communication or of parsimonious communication with articulated language ${ }^{14}$, but it refers to the substantiation or the profound causality of the differences between the role of image and that of articulated language.

Opposed to those who praise the supremacy of image in many moments of current communication and consider it a technical, objective and inevitable change - which means, in this case, independent from social relations and from people's control over it - so, change to which people only have to adapt and to integrate enthusiastically, the thesis proposed in this article is that on the contrary, the supremacy of image over articulated discourse, namely over theory and the theoretical capacity of human beings, is: a) a recession/rebound in the constitution and development of the human specificity and b) the manifestation of power relations, namely of dominance-submission relations.

We must not confuse (just as Nadin, 1997 does), or judge uniformly the image as predominant means of entertainment and communication (photographs sent via social networks and received on mobile phones and tablets, the endless viewing of televised images, video games and commercials) with the means of creation and dissemination of such image, with IT

14 See Twitter, a short message communication network with a limit of 140 words. But communication networks as such - besides Internet - are meant, by definition, to communicate articulated information as less as possible, but rather visual images/addresses for (photographs, clips, videos, online games, films). (which, however, does not create and disseminate only images, but also text and oral discourse). Because essentially and not conjecturally, the contents of image and text and oral discourse is not dependent on technical means, but on the decisions of the people controlling the education processes and social communication, as well as the dominance-submission structure of social relations: illogical messages, incentives for aggression, for the deletion of the critical capacity of people and for the rarefaction of the criteria for distinguishing between evil and good, for assuming those "anti-causal value judgements" to which Konrad Lorenz refers when analyzing the disinhibition of the preservation instinct of the life of the species (the inhibition mechanism of the aggressive instinct having a moral responsibility) (Lorenz, 2002), these are all generated not by IT, but by the $d e$ cision-makers using it.

The arguments for the above-mentioned thesis refer to the human ontology. Only articulated language examines the behavior of man in a critical manner in terms of logic, namely in terms of criteria and principles which means that man is the one who knows to separate good from evil and choose good. Of course language can transmit false meanings and significances just like writing; but just like image, I add however the solution is not its removal and replacement with images. The manner in which oral articulated language and written language is manifested is similar.

If people can infer $n$ things concerning images, in order to follow these inferences/for they to be a source of significances and a guidebook for people, they must express them in an articulated manner: otherwise, images fly as fast as words compared to writing; yet this articulated form of expression - which de- 
scribes and judges meanings revealed by images, which selects meanings in this way and which fights to give them the most adequate expressive verbal form to people's intuition - is achieved by "one's own toil" (Plato, 1925, 275a). And if we understand that even writing may be silent (namely not provides answers to people) just like a painting that always shows the same thing (Plato, 1925, 275d), then we realize one more time that, even though there are similarities between image and language, there is also the essential difference of the logos manifested only through word, only through the unfolded and articulated logic of the natural language: consequently, if language can be represented by images, images must ultimately be expressed by language in order to be vectors of meaning. Because images can "avoid literal truth" and they are "malleable", but under no circumstance can they being described as representing reality better ${ }^{15}$ and as defining subjects better. Indeed, they are not simply illustrations of texts, so we must acknowledge not only the complimentary character of articulated language and of image ${ }^{16}$, but also their limitations ${ }^{17}$ and especially the inability of an image to articulate meanings reproduced in an articulated manner. And this conclusion enables us to mention also special languages (of different sciences or programming languages) as transmitting diminished meanings and, ultimately,

15 Undoubtedly, mathematical reality is better described by symbols, equations, formulas: but all these form, let us not forget, also a language.

16 For example, the fact that modern medicine can no longer develop without imaging and without learning from images.

17 Images can render what text cannot, and also the reverse is equally valid. Images can indeed render the invisible for the space of experience described with the help of natural language, but text can render meanings and significances that encompass and transcend $n$ worlds of experiences through a programming language or through images. only with the help of natural language: even if, for example, programming languages are based on reduced ambiguity, while natural language contains ambiguous words, metaphors and many other figures of speech.

Images can be more accessible, but their above-mentioned inability makes this accessibility to come to positive fruitfulness only together with the development of language by each user of images. Only articulated language allows the identification of nuances, the capacity to express what man sees and envisages, the capacity to understand and express paradoxes (Deleuze, 1969, pp. 11, 16): and thus, to interpret them.

\section{Image and Writing}

Writing has been an administrative instrument, as it is well known: the collection of tributes had to be accounted for and, in order to accomplish this function, leaders needed scribes. Commerce also needed the memory of writing, and the domain required the simplification of signs, as we know from the Phoenicians. Writing rationalizes, makes potential discrepancies in speech disappear: because speech transmits emotions (Rousseau, 1856, p. 502), while writing transmits information; written language "loses thus from its force, but gains in clarity" (Rousseau, 1856, p. 503). Writing became, obviously, a means of cultural memory, but the importance of writing emerged when it had to be read and understood by as many people as possible (not only be leaders, traders and scribes). In this respect, writing was connected to the civilization and the knowledge of law: accordingly, connected to a technical knowledge and this was not necessary only for some. The Greek polis was the place where writing 
and reading was generalized amongst citizens: in order for them to be able to understand the norms of social relations. That is why Plato compared oral discourse and writing to the wise ploughman who "bears in mind the rules of agriculture": writing is always the sign that people also understand what they are writing and, inherently, that they write true things (they don't "write on water") through the "dialectic art" of analysis, because only these true things are truly known (Plato, 1925, 276b, 276c, 276d, 277b-c). (The others are forgotten and are only noise).

However, let us remember the ideas from Phaedrus about writing, in light of the already old, but so important analysis of Derrida (1972), precisely because they meet those which undervalue the text. As mentioned above, dialogue rejects only the bad writing, not the good one which is made of "knowledge of the just and the good and beautiful ....(and) defend themselves by arguments" (Plato, 1925, 276c). Good writing is the one which does not replace argumentation with "myths" explained only to please (because such an explanation of myths is easy compared to the attempt to decipher new issues such as the process of knowledge and expression of the self) (Plato, 1925, 229c-230a).

Writing acts like a pharmakon, like a drug, but the drug can be a medicine/remedy as well as a poison, so that, writing - as well as speech (Plato, 1967, 459a and b; 501d and e; but let us remember Aesop's fable on language) - may also be used in a contradictory manner: those who write only by copying ideas are alleged connoisseurs, and those who read these things and do not think about it as if hypnotized are mere imitators that mimic knowledge. If writing is repetition without knowledge, it is a denial of the rational essence of man; because indeed writing and basically speech as well (both of them constituting logos) are based on the understanding supervising them, the logic of discourse in the mind which simply renders Being as such (the ancient pattern of human logos corresponding to the cosmic one appears once more). Therefore, ultimately, Plato opposes to the writing as drug/poison not orality, but the idea, truth, law, episteme, dialectic, philosophy (Derrida, 1972, pp. 331-332).

At a first glance, unlike Plato, Rousseau seems to have considered writing generally as inferior to speech, because writing transmits accuracy, it does not respond to the heart, but to the mind, hence it gives a uniform to feelings, to intentions. The spoken word (Rousseau, 1856, pp. $499,501)$ is even "annoying". Such a "representative" (Derrida, 1967, p. 207) writing impoverishes human language, because it is a translation of the natural expression of/a translation of thought into words. All these, writing and speaking, are "signs or images" (Rousseau, 1856, p. 513). On the other hand, however, the basis just like in the case of a melody or a painting - is represented by the meanings transmitted: a melody does not transmit only sensations pleasant to the ear, neither does painting impress only by a pleasant combination of color, they transmit moral perspectives ("moral effects with moral causes") and the "drawing" (Rousseau, 1856, p. 513), the sketch, the idea. Moreover, the transmission of sounds always involves movement, the change of life, while painting only renders it, "it is dead" (Rousseau, 1856, p. 518), so that not only the perfection of articulated language connected to argumentation processes, to philosophy and rhetoric led to the decrease in importance of music in ancient Greece ${ }^{18}$, but as the moral sens-

18 Rousseau, 1856, p. 518: “as soon and Greece was full of sophists and philosophers, there were no more famous poets or musicians". 
es have decreased and continue to diminish because people are interested in persuading and not responding to real emotions/emotional issues, melody has become a mere ingenious combination of sounds (separating itself from word $-\mathrm{AB}$, namely from the auditory signs transmitting emotions - and not a transmitter of moral effects) (Rousseau, 1856, p. 521) as did spoken language. It seems that "our languages are worth more in writing than spoken" (Rousseau, 1856, p. 512). As a result, also in Rousseau's case, the evaluation of writing compared to spoken language analyzes the moral meanings transmitted or not by one or the other ${ }^{19}$.

The reified form of language as writing was named "literacy" by Mihai Nadin. And the transfer to the predominance of image created and transmitted by information technology - as a transfer to the civilization of illiteracy. The meaning of this latter word is extremely metaphorical: precisely in order to support the thesis of the predominance of image nowadays and the positive capitalization of this predominance.

The author's arguments are: i) images have heuristic dimensions, while "literacy lacks" (Nadin, 1997, pp. 147-8) such dimensions, ii) images (transmitted through the new IT media) are more practical than texts and correspond to the need of speed and efficiency of today's society, iii) and they also allow for greater connectivity (instantaneous; in real time) between people and between people and reality. This makes them citizens of the world communication network/networks and able to overcome, in such manner, the elitism imposed by language and literacy (Nadin, 1997, p. 358). As a result, the

19 Also see Derrida, 1967, p. 203: "The word that Rousseau raised above writing is the word as it should be, or rather, as it should have been". demonstration briefly refers to the social ambivalence of image (the fact that messages transmitted through images can also consolidate elitism, and that images are different in terms of accessibility and that they can exacerbate alienation) and "of course" it excludes the field of social, political and economic causes of this ambivalence.

I would counter the above thesis only the idea that as language and writing gradually democratized according to the social processes of leadership and labor ${ }^{20}$, therefore as writing and culture in general were the battlefield between the dominant elitism and the democratization tendencies, so the image is a space of social struggles. To consider otherwise means simply subscribing to the techno-optimism à la Toffler etc.

Text is the basis of long cycles of use - and these cycles also include the time for reflection and for connecting things - while images sustain short cycles, in which the fast replacement if images is connected to an ephemeral and perishable character which can do harm if deemed constitutive values of the behavior pattern, then if they are disconnected from the logical and moral judgments concerning things. It all depends both writing and image - on how we use them: unread books are, indeed, dead, but people have always constantly written and read something else. Replacing books/analytic texts with Wikipedia and popular pages on the Internet does not necessarily mean progress, except of course in terms of accessibility: because it also depends on what pages we chose and how much and what we read from such pages and how we think about

20 See for example, the generalization of writing through the citizens of classical Athens, (Marrou, 1948, 1981): primary school as a rule already in the $3^{\text {rd }}$ and $2^{\text {nd }}$ century B.C. and equally for boys and girls. 
them and with their help, and also, it depends on how we express all these.

In the attempt of an ontological deciphering, a superficial declaration counters the text which conceals to the image which reveals. However: i) an image can also conceal, namely it can conceal the causes and consequences of the situation translated into images, and without understanding these - which is done only discursively - image loses its relevance, its power to reveal reality; in this respect, image is like an opinion opposed to science/substantiated knowledge (in Plato and Aristotle); ii) on the other hand, why can the text conceal? Because, of course: it is difficult to render the meanings and intentions. And also because of an ideological cause: the individual perspective - achieved from a position of experiences, of the influences suffered and of one's own creation, but which is situated, consciously or not, depending on social ruptures - tends to abstract from complexity, to reduce it, to exclude it from the field of consciousness and the one of articulated language, to cover aspects of reality which are interconnected with those described by a text. Only critical and "all the way" critical positions exceed unilateral views. And text conceals because it is always, just like an image, a slice of reality: but a good text is never considered to cover/mask/conceal, precisely because its value consist in its capacity to render such a slice of reality (logically, with arguments, in relation to other slices etc.).

Probably what gives text the highest value compared to image is the truth. Only text more than oral language marked by immediate reaction, inherently fragmented and characterized by ephemeral - evidences truth about things: truth is not, in a good text, absolute and definitive, of course, but it is proved by a long series of arguments; consequently, we are talking about the truth depending on the analysis made with respect to that slice of reality. Only truth - or what seems plausible, true, but this is not relevant here - is the knowledge on which the understanding of the world is built. Image transmits truth only if supported by, and integrated into language and text.

And if today the dominant message is propagandistic so that receivers accept the relation of submission and not question it except in a superficial and fragmented sense which too arrives to the inevitability of the status quo -, and society is controlled precisely through the supremacy of image and by becoming a society of the spectacle, as Guy Debord remarked since 1967 (see also Bazac, 2017), the cause is not the development of image technologies, but the internal logic of late modernity. The harmfulness of the predominance of image consists precisely in the human pattern it creates in this late modernity: the pattern of a man who must not know, but who must receive images with simple meanings, with as less text/articulated language as possible, and thus, "be happy".

\section{In Lieu of Conclusions: While the Era of Image is Celebrated, the Society of Knowledge and Learning is Supported}

The first idea resulting from this article is the complimentary character of text and image, because these two entities are themselves not only interdependent but also interconnected: in its turn, image narrates and text makes us see, illustrates. What is truly important is that this ontology is not refuted by the simplifying and dividing practice.

Then, image, as well as text and also as oral 
language, is worth as much as many meanings it transmits and as what quality of meanings it transmits. The perspective of this article is not of lamentation in front of the current mass culture and the one-dimensionality of the human pattern imprinted nowadays, but that of discussing the causes and of interpreting the concepts in relation to this discussion. The conclusion of this analysis is indeed the classical one: the diminishing of preoccupations, of the ability and time for logical articulation of the reference to the world means the decline of man. To live only by viewing, creating and receiving images, by wanting to consume as many images as possible and only to be entertained, by "not being bothered"21 with what is outside images, with what is "too" complex and to cram it into the category of mystery for which the solution is the extramundane being means, basically, the disappearance of man.

Image becomes autonomous in relation to text - as well as, initially, text became autonomous in relation to image and just as well as all aspects of reality may also be studied separately - but, ultimately, nothing replaces articulated language and writing.

The predominance of image over logical language means the accenting of the relative character of knowledge, not in the sense of understanding their historical determination (because, indeed, knowledge is relative from this point of view of historical and social conditioning), but in the moral sense of the attitude towards values, losing the moral criteria. And knowledge deemed to be so relative is no longer an instrument used for understanding: emoticons are sufficient in this respect.

The predominance of image over oral or

21 To not be bothered has become a slogan internalized as a result of the bombardment made by the social media organized around consumption. written discourse - I used the concept of discourse, instead of communication - means that we no longer consider reality as being real, but only as a series of images. As a result, people are no longer shuddering when faced with the reality of wars and violence: they no longer react, but they look at other images. Yes, image must not justify itself, it is sufficient to itself: man can see the horrors of war, but the refusal of horror - and the decisive refusal - although it can start from the feeling generated by the image of war, is based on articulated language: the only one which analyzes, demonstrates, gives arguments, contrasts with other arguments, establishes, gives reason to things. And if man fails to control also because of a week discursive experience the argumentative potentiality of discourse, he cannot oppose the horror of which he is convinced, and becomes a passive receiver of the decisions proposing horrors.

If images incline the balance in the economy of signs, people will simplify the meanings transmitted by messages and will be accustomed to responding to images with images, and to simplified meanings with simplified meanings.

The popularity of video games is owed (Nadin) to the fact that even children understand them. But what do they understand from such games? And in this case, first of all, we should not forget that video games are "a simulation for pleasure, with a coherent and well-tuned imaginary world" (Triclot, 2011, p. 5), an “instrumented experience" (Triclot, 2011, p. 6), a "potential space in which a fraction of reality is subject to a magic control, which maintains the object in a suspended state, not entirely my creation, nor a mere external event" (Triclot, 2011, p. 11), and which limits human experience to war/aggression, mimicry, the power of the arbi- 
trary and dizziness/disorientation. In this space, confusion between reality and imaginary ${ }^{22}$ goes hand in hand with the simplification of human reactions: in order to fulfill the requirements of the game program.

Secondly, the focus on the virtual world because real life is too difficult to bear - annuls the elements of attention precisely from the human's presence in real social relations and in relation to the real social and natural environment: the characteristic of this type of presence, lacked of attentive scrutiny, is superficiality. The behavior pattern in a video game is the surf one, of valorizing discontinuity by jumping and bouncing off in order to achieve the goals of the program, and as a result, in the real world everything seems to be too cumbersome, too slow, impossible and so long that - of course, not only because of the predilection for the virtual world of video games - it can no longer be understood and actively addressed. In this shift of attention from real to virtual one can speak of attention deficit whose consequences are dramatic (Gallagher, 2009; Cantwell, 1996). So that, not even the interactivity ${ }^{23}$ of games and of the presence in the virtual space is able to cancel the precariousness of meanings which the player is capable of and which he may transmit: if, once again, life in images weighs more than the life in the rational articulation of the world.

Thought reduced to the mental processing of an image means the drastic diminishing of the ability to reason and of its instruments, first of all of words. The predominance of image in the relations with others decreases the autonomy of thought over the self: such thought de-

22 See the most recent form of such confusion: the Pokemon Go game.

23 Interactivity is more or less Nadin's only argument to praise the predominance of image over articulated language. pends on the image of the others about the image transmitted to them about oneself.

However, once again, judging an image and its predominance nowadays must not be disconnected from judging the entire ensemble of social relations, processes and phenomena; just as, the beneficial use of image - the development of man's power to act precisely with the help of imagery - must be highlighted from the perspective of a holistic critique: which, according to the quoted example (Zick Varul), deconstructs the place of the visual in today's society starting precisely from the positive valences of image.

For this reason, not only that we must not counter the "bad" image to the "good" text such contraposition being just as simplistic as its adverse stand promoting the "good and revolutionary" image against the "old-fashioned" text but we must apply here the former ancient Delphic principle of measure: nothing in excess! Namely we must understand the danger of the too much - together with the danger of the too little -, the importance of prioritization in the scale of goals and means which people must have, and of the adequacy of means to goals according to the consequences of both.

Therefore, the solution suggested in this article is not a techno-phobic one, of return to the puritan world of the dominance of text and in which such phenomenon would also take place by class-related dominance. On the contrary, if we consider the responsibility for the facts and consequences of people's actions, then all types of ignorance, that related to text and also that related to image are to be rejected: but also the conditions which support this ignorance. 


\section{REFERENCES}

Bazac, A. (2017). Fifty Years from Guy Debord's La société du spectacle/The Society of the Spectacle. Retrieved May 12, 2018 from:

http://egophobia.ro/?p=11893.

Benjamin, W. (1936). The Work of Art in the Age of Mechanical Reproduction. Retrieved May 10, 2018 from:

https://www.marxists.org/reference/su bject/philosophy/works/ge/benjamin. htm.

Berkeley, G. (1708). An Essay towards a New Theory of Vision. Retrieved May 11, 2018 from:

https://en.wikisource.org/wiki/An Es say Towards_a New Theory of Vi sion.

Berkeley, G. (1733). The Theory of Vision, or Visual Language, Shewing the Immediate Presence and Providence of a Deity, Vindicated and Explained. London: Printed for J. Tonson in the Strand.

Cantwell, D. P. (1996). Attention Deficit Disorder: A Review of the Past 10 Years. Journal of the American Academy of Child \& Adolescent Psychiatry, 35(8), 978-987.

Darnton, R. (2010). Poetry and the Police: Communication Networks in Eighteenth-Century Paris. Cambridge, MA: Belknap Press.

Debord, G. (1992). La Société du Spectacle (1967). Paris: Les Éditions Gallimard.

Deleuze, G. (1969). Logique du sens. Paris: Les Éditions du Minuit.

Derrida, J. (1967). De la grammatologie. Paris: Minuit.
Derrida, J. (1972). La Pharmacie de Platon (1968). In Derrida, La dissémination. Paris: Éditions du Seuil.

Gallagher, W. (2009). Rapt: Attention and the Focused Life. New York: Penguin Books.

Lorenz, K. (2002). On Aggression (1963), (M. K. Wilson Trans., 1966). London and N.Y.: Routledge.

Marrou, H.-I. (1948, 1981). Histoire de l'éducation dans l'Antiquité, Tome 1. Le monde grec, Tome 2. Le monde romain. Paris: du Seuil; Paris: Points.

Marx, K. (1854). The English Middle Class. Retrieved May 09, 2018 from: https://www.marxists.org/archive/mar x/works/1854/08/01.htm.

Moscovici, S. (2000). La mentalité prélogique des primitifs et la mentalité prélogique des civilises. In S. Moscovici (dir.), Psychologie sociale des relations à autrui (ch. 9, pp 208-231). Paris: Nathan/HER.

Nadin, M. (1997). The Civilization of Illiteracy. Retrieved May 15, 2018 from: http://www.gutenberg.org/files/2481/ 2481-pdf/2481pdf.pdf?session id=7ae8bb28d537c4f d2276ddafef767f1cc89ec6be.

Plato (1921). Cratylus. In (H. N. Fowler, Trans.) Plato in Twelve Volumes, vol. 12. Cambridge, MA: Harvard University Press; London: William Heinemann Ltd.

Plato (1925). Phaedrus. In (H. N. Fowler, Trans.) Plato in Twelve Volumes, vol. 9. Cambridge, MA: Harvard University Press; London: William Heinemann Ltd.

Plato (1925). Timaeus. In (W.R.M. Lamb, 
Trans.) Plato in Twelve Volumes, vol.

9. Cambridge, MA: Harvard University Press; London, William Heinemann Ltd.

Plato (1967). Gorgias. In (W.R.M. Lamb, Trans.) Plato in Twelve Volumes, Vol. 3. Cambridge, MA: Harvard University Press; London: William Heinemann Ltd.

Postman, N. (2005). Amusing Ourselves to Death: Public Discourse in the Age of Show Business (1985). (A. Postman, New Introd.). New York: Penguin Books.

Rousseau, J.-J. (1856). Essai sur l'origine de slangues (1781, posthumously). In Rousseau, Oeuvres complètes, Tome troisième. Paris: Firmin Didot Frères.
Sloterdijk, P. (2009). Rules for the Human Zoo: a Response to the Letter on Humanism. (1999). Environment and Planning D: Society and Space, Vol. 27, 12-28.

Triclot, M. (2011). Philosophie des jeux vidéo. Zones, mai.

Varul, M. Z. (2013). Towards a Consumerist Critique of Capitalism: A Socialist Defence of Consumer Culture. Ephemera. Theory \& politics in organization, 13(2), 293-315. Retrieved May 27, 2018 from:

http://www.ephemerajournal.org/contr ibution/towards-consumerist-critiquecapitalism-socialist-defenceconsumer-culture. 